https://helda.helsinki.fi

\title{
Game theory and fisheries
}

\section{Gronbaek, Lone}

2018-07

Gronbaek , L , Lindroos , M , Munro , G \& Pintassilgo , P 2018 , ' Game theory and fisheries ' , Fisheries Research , vol. 203 , pp. 1-5 . https://doi.org/10.1016/j.fishres.2017.11.027

http://hdl.handle.net/10138/313339

https://doi.org/10.1016/j.fishres.2017.11.027

cc_by_nc_nd

acceptedVersion

Downloaded from Helda, University of Helsinki institutional repository.

This is an electronic reprint of the original article.

This reprint may differ from the original in pagination and typographic detail.

Please cite the original version. 


\title{
Game Theory and Fisheries
}

\author{
Lone Grønbæk \\ Department of Business and Economics \\ University of Southern Denmark \\ Odense, Denmark \\ $\lg @$ sam.sdu.dk \\ Marko Lindroos \\ Department of Economics and Management \\ University of Helsinki \\ Helsinki, Finland \\ marko.lindroos@ helsinki.fi \\ Gordon Munro \\ Vancouver School of Economics \\ University of British Columbia \\ Vancouver, Canada \\ gordon.munro@ubc.ca \\ Pedro Pintassilgo ${ }^{1}$ \\ Faculty of Economics \\ and Research Centre for Spatial and Organizational Dynamics \\ University of Algarve \\ Faro, Portugal \\ ppintas@ualg.pt
}

\footnotetext{
1 Corresponding author. Address: Faculdade de Economia, Universidade do Algarve, Campus de
} Gambelas, 8005-139 Faro, Portugal. Tel: (351) 289800 915; Fax: (351) 289800063. 


\begin{abstract}
Game theory studies the strategic interactions between and among decision makers, players, through mathematical models called games. This paper presents an overview on the evolution of the application of game theory to fisheries economics. The first applications emerged in the late 1970s, focussing upon internationally shared fish stocks. This occurred in the context of the UN Third Conference on the Law of the Sea, and the 1982 UN Convention on the Law of the Sea. During the 1980s and early 1990s the application of game theory to fisheries focused mainly on transboundary fish stocks. Thereafter, the applications to straddling fish stocks developed significantly, through the use of coalition games. This was as a consequence of the mismanagement of these stocks, and the management regime brought forth in response by 1995 UN Fish Stocks Agreement. The application of game theory to the management of national/regional fisheries is a new research frontier, as it is still much underexplored, when compared to international fisheries. This paper also summarizes the main research developments of a set of nine papers selected for this special issue on Game Theory and Fisheries.
\end{abstract}

Keywords: game theory, fisheries economics, international fisheries, national fisheries. 


\section{Introduction}

This Special Issue owes its origin to a Special Session on Game Theory and Fisheries Economics at the $18^{\text {th }}$ Biennial Conference of the International Institute of Fisheries Economics and Trade (IIFET) held in Aberdeen, Scotland, in July 2016. The Special Session was mounted in recognition of the growing importance of the theory of strategic interaction, game theory, to fisheries economics. So successful was the Special Session that it was felt that further steps should be promptly taken. The Special Issue of this journal is the result.

Several papers presented at the Special Session were, as hoped, revised and submitted for publication in this Special Issue. It was decided, however, that submissions should not be restricted to those participating in the IIFET Conference Special Session. All IIFET members, with an interest in game theory, were invited to make submissions.

A game theoretic situation, let us be reminded, is deemed to arise when the actions

of one "individual" have a perceptible impact upon one or more "individuals", leading to a strategic interaction between or among the "individuals". The relevance of the theory of such strategic interaction, game theory, to the economics of fisheries management has evolved gradually over time.

\subsection{Evolution of the application of Game Theory to Fisheries Economics: The role of} international fisheries

While increasing recognition is now being given today to the importance of game theory in fisheries economics, such was not always the case. The origin of modern fisheries economics is commonly traced back to the publication of H. Scott Gordon's seminal article, "The Economic Theory of a Common Property Resource: The Fishery" (Gordon, 1954). 
The year 2019 will mark the $65^{\text {th }}$ anniversary of that article. Up until the $25^{\text {th }}$ anniversary of the Gordon article, game theory played little or no role in fisheries economics. The year 2019 will also happen to mark the $40^{\text {th }}$ anniversary of the first article on a fisheries economics topic explicitly employing game theory (Munro, 1979).

Why this lack of interest in game theory? The Gordon model contrasts a perfectly competitive fishing industry, under open access conditions, with that of a sole owner of the fishery. In either case, there is no strategic interaction, and thus no need for game theory. It is true that in the years, indeed decades, prior to the late $1970 \mathrm{~s}$, much of what regulation there was of fisheries was done at the international level, where there was an obvious strategic interaction among the states involved. Fisheries economists of the day, to the extent that they commented on the fisheries management at the international level, glossed over the strategic interaction. A possible reason for this paucity of interest in strategic interaction lies in the claim that, while the application of game theory to economics can be traced back to the mid-1940s, such application did not really take hold until the 1970s (see, for example, Bierman and Fernandez, 1993).

The primary event, triggering the introduction of game theory to fisheries economics, was the UN Third Conference on the Law of the Sea, 1973-1982, which had a revolutionary impact upon the management of world fisheries. The Conference brought forth the 1982 UN Convention on the Law of the Sea, which led, in turn, to the advent of the Exclusive Economic Zone (EEZ) regime. The negotiations over fishery issues in the Conference were all but completed by 1975 , with the result that several coastal states, e.g. Canada, United States, implemented EEZs before 1982. In any event, it was estimated that, if the EEZ regime became universal, which it is close to being, the EEZs would encompass 
90 per cent of the commercially exploitable marine capture fishery resources (Munro et al., 2004).

The EEZ regime brought the management of internationally shared fishery resources to the fore, where an internationally shared fishery resource is deemed to be any fishery resource exploited by two or more fishing states (Munro, et al., 2004). Most fishery resources prior to the Conference had, of course, been internationally shared, a fact, which had not aroused much interest. The EEZ regime made the management of internationally shared fishery resources an issue that was inescapable.

Due to the mobility of marine capture fishery resources, the typical coastal state was forced to recognize that some of the fishery resources within its EEZ would almost certainly move into the EEZs of one, or more neighbouring coastal states - transboundary stocks - and/or would cross the EEZ boundary into the adjacent high seas, where they

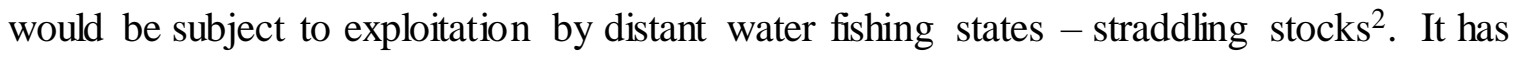
been estimated that, under the EEZ regime, internationally shared fishery resources account for one third of the aforementioned commercially exploitable marine capture fishery resources (Munro, et al., 2004). In the early days of the 1982 UN Convention on the Law of the Sea, it was thought, mistakenly, that, of the two, only transboundary stocks were truly important ${ }^{3}$.

If the coastal states of the world could not ignore the resource management problem posed by transboundary stocks, then neither could fisheries economists. Strategic interaction between or among the coastal states sharing a transboundary stock lies at the

\footnotetext{
${ }^{2}$ One should also note, as of yet not of great importance, discrete high seas stocks, to be found exclusively in the remaining high seas.

${ }^{3}$ Recall that it was estimated that only 10 per cent of the commercially exploitable marine capture fishery resource would be found in the remaining high seas.
} 
heart of the resource management problem. Fishery economists, investigating the economic management of these stocks, found themselves compelled to bring to bear both the theories of non-cooperative and of cooperative games. The first articles, employing game theory, on the economic management of transboundary stocks appeared in 1979 and $1980^{4}$.

It is impossible to emphasize too strongly that this application of game theory did not arise from economists skilled in game theory seizing the opportunity to display their prowess. It arose, rather, from economists being forced by the policy issue at hand to apply game theory and to seek, if necessary, assistance in so doing.

The period of the 1980s and early 1990s saw a series of refinements of and extensions to the game theoretic analysis of the economic management of transboundary stocks. Then, in the late 1980s, a new internationally shared fish stock management problem began to emerge.

The earlier view that straddling stocks are unimportant was revealed by the late 1980s to have been quite simply wrong. Case after case of resource mismanagement involving straddling stocks arose, mismanagement, which could not be ignored. The UN found itself compelled to convene another conference, popularly referred to as the UN Fish Stocks Conference, 1993-1995. The Conference brought forth what is popularly referred to as the UN Fish Stocks Agreement, designed to supplement the 1982 UN Convention on the Law of the Sea (Munro et al., 2004).

The UN Fish Stocks Agreement led to a new regime emerging, that of Regional Fisheries Management Organizations (RFMOs). A RFMO is designed to bring together

\footnotetext{
${ }^{4}$ In addition to the Munro (1979) article, referenced earlier, there were articles by Clark (1980) and Levhari and Mirman (1980).
} 
relevant coastal and distant water fishing states for the management of a straddling stock, or a set of such stocks. Examples are provided by the Northwest Atlantic Fisheries Organization (NAFO) and the Western and Central Pacific Fisheries Commission (WCPFC).

The economic management of straddling stocks through RFMOs is an undertaking far more formidable than is the economic management of transboundary stocks. In attempting to analyse the economic management of straddling stocks, it was soon found that simple non-cooperative and cooperative game models are quite inadequate for the task at hand. Far more sophisticated game theory models are required, with partition function games models proving to be the most successful so far ${ }^{5}$. Much more remains to be done, e.g. analyzing the consequences of uncertainty, as evidenced by several of the articles in this Special Issue.

\subsection{Game Theory and the management of national/regional fisheries: The new frontier}

With respect to fisheries, the UN Third Conference on the Law of the Sea did far more than make the management of internationally shared stocks an unavoidable issue. The Conference massively increased the importance of management of fishery resources at the national/regional level. Prior to the Conference, coastal state jurisdiction over fishery resources off the coastal state coast extended to a maximum of 12 nautical miles. With the coming of the EEZ regime, that jurisdiction was extended to 200 nautical miles ${ }^{6}$. This then raises the question of whether game theory has a role to play in the analysis of the economic management of fishery resources within the EEZ. The short answer is that, while game

\footnotetext{
${ }^{5}$ See, for example, Pintassilgo (2003); and Pintas silgo et al. (2010).

${ }^{6}$ Approximately $370 \mathrm{~km}$.
} 
theory does indeed have a role to play, the application of game theory to the economics of fisheries management at the national/regional level lags far, far behind the application at the international level. With that being said, one of the articles to follow does in fact apply game theory at the national/regional level.

Fisheries management at the nationa $/$ regional level has developed in stages, with the first being what is popularly referred to as Regulated Open Access (Wilen, 1985), in which the national resource manager restricts the season by season harvests in order to conserve the fishery resources, but places no limits on the number of vessels seeking to compete for shares of the restricted harvests. The economic analysis of Regulated Open Access legitimately continued with the $\mathrm{H}$. Scott Gordon assumption that the relevant fishing industry is perfectly competitive. Once again, there was no strategic interaction, and thus no need for game theory.

Regulated Open Access was seen to lead to resource rent dissipating excess fleet capacity. The response by the national resource managers was to attempt to limit the fleet size in any given fishery through so called license limitation or limited entry schemes. With the number of vessels limited to a given fishery, the assumption that the relevant fishing industry is perfectly competitive ceases to be valid. Strategic interaction among fishers, vessel owners, becomes a distinct possibility.

Under the original limited entry schemes, the resource managers found it very difficult to control true fishing capacity - the ability to catch fish - with control of the number of vessels proving to be markedly inadequate for that purpose. Furthermore, the vessels allowed into the fishery were virtually invited to compete for shares of the restricted harvest. One had the makings of a competitive fisher game, which came to be analysed by 
Wilen (1985). His analysis reveals an almost textbook example of a Prisoner's Dilemma game, in which competing vessel owners are driven to expand fishing capacity, even if all recognize that by so doing resource rent will be dissipated.

Disappointment with the original limited entry schemes has led to increasing emphasis being given to what the FAO of the UN refers to as incentive adjusting approaches to fisheries management, in which attempts are made to modify the perverse fisher incentives leading to resource overexploitation and excess fishing capacity, rather than just attempting to block the fishers as they respond to these perverse incentives. This has taken two forms, taxes (positive and negative) and harvesting rights schemes.

Taxes have been but little used. Their use, however, have been studied by economists, largely by applying Principal-Agent analysis (leader-follower games) (e.g. Vestergaard, 2010).

Harvesting rights schemes are best thought of as modifying the original limited entry schemes. Rather than have fishers (vessel owners) compete for shares of the restricted harvest, shares are allocated to the fishers. The allocation may be done on a collective basis - cooperatives - or on an individual basis - IQs, individual harvest quotas. This raises the possibility of cooperation among harvesting rights holders. Indeed a successful fisher cooperative is a stable cooperative game, virtually by definition.

There is a further possibility, however, namely that of cooperation between the fishers and the resource manager, what one might call a double level of cooperation. A decade old article by Kronbak and Lindroos (2006) provides a basic framework, but little has been done since that time. 
This issue was raised at the aforementioned Special Session at the $18^{\text {th }}$ IIFET Conference in 2016 in a paper by Grønbæk et al. $(2016)^{7}$. The paper commences by reviewing the 2006 Kronbak and Lindroos analysis in which the resource manager is seen playing a leader-follower game with the fishers (industry), with the fishers responding by engaging in competition with one another, or engaging in partial cooperation or full cooperation. It then goes on to examine that history of a now well documented Canadian fishery, the British Columbia groundfish trawl fishery (see: Wallace et al., 2015).

The Canadian fishery was at first managed under the original type of limited entry scheme, and was marked by intense competition among the fishers, and competition between the fishers and the resource manager. The management scheme was reformed, with the fishery being put under an IQ - ITQ (individual transferable quotas) - scheme. There is abundant evidence that, over time, the competitive fisher game has been transformed into a cooperative one. Furthermore, the competitive industry-resource manager game has evolved into a cooperative game.

Of perhaps even greater significance, there is evidence of switching over time of the leader-follower roles. The industry came under attack from NGOs for habitat destruction. The industry took the initiative in resolving the issue. The support and approval of the resource manager (government of Canada) were essential, but the fact remains that the role of the resource manager was a passive one (Wallace, et al., 2015). Furthermore, there have been instances in which the industry has pressured the resource manager to reduce season by season harvest allowances (TACs).

\footnotetext{
7 The paper was not included in this Special Issue, because the paper is a call for future game theoretic research, rather than a piece of game theoretic analysis.
} 
One cannot claim that the Canadian experience is unique. There are almost certainly other examples of this double level of cooperation, waiting to be researched.

Be that as it may, there exists no adequate game theoretic analysis of this double level of cooperation. Grønbæk, et al. (2016) argue that game theoretic tools not yet employed in fisheries economics, e.g. partnership games, will have to be brought to bear.

In any event, the application of game theory to the analysis of the economic management of fisheries at the national/regional level is a new frontier. This question, let it be added, will be explored at some length in the book, now in preparation, Game Theory and Fisheries Management: Theory and Applications, by Grønbæk, Lindroos, Munro and Pintassilgo ${ }^{8}$.

With the stage now set, we turn to a summary review of the articles to follow.

\section{Recent Research Developments: The Articles Reviewed}

In turning now to discuss the main contributions of the papers published in this Special Issue, the papers are reviewed in the sequence in which they appear in the volume.

2.1 Hannesson (2017) addresses the management of internationally shared fish stocks using the mackerel stock in the Northeast Atlantic as a case study. The absence of a formal agreement in this fishery would lead us to expect the non-cooperative outcome of a Nash-Cournot game. However, that does not occur, as countries seem to be engaged in informal cooperation, adopting fishing strategies close to those under formal cooperation. The author models this situation as a game in which cooperation is supported through

\footnotetext{
${ }^{8}$ The book (Grønbæk et al., forthcoming) is to be published by Springer International Publishing AG, with a hoped for publishing date of mid-2019.
} 
implicit or explicit threat strategies, making non-cooperation unattractive for individual players. The adequacy of the zonal attachment principle for sharing the cooperative catch quota is also addressed. According to this principle, countries should get the same share of the total catch quota as they have of the stock in their respective zones. It is shown that typically this principle does guarantee that small players have incentive to accept the cooperative solution.

2.2 The management of internationally shared fish stocks in the Northeast Atlantic is also the research topic of Salenius (2017). The paper studies the joint effects of the interactions between harvesting countries and fish stocks, in the context of a multispecies fishery composed by three pelagic species: Norwegian spring-spawning herring, mackerel and blue whiting. The management scenarios consider whether the harvesting countries behave cooperatively or non-cooperatively, and whether multispecies or single-species are accounted for. The central goal of the paper is to evaluate the effects of different types of fisheries management on a multispecies fishery. The author concludes that the difference between single-species management and multispecies management is very relevant under cooperative management, but much less so under non-cooperative management.

2.3 Górniewicz and Wiszniewska-Matyszkiel (2017) also approach the management of a shared multispecies fishery. The authors adopt a dynamic noncooperative game with discrete time and infinite horizon, modifying the classical twoplayer, two-species "Fish Wars" model by Fischer and Mirman (1992). The paper considers the possibility of stock depletion and the Alee effect, which means that below some critical level of biomass, a species starts to degenerate and becomes extinct. The Nash equilibria of the game is obtained under some parameter restrictions. This coincides with 
the strategies obtained by Fischer and Mirman (1992), when both biomasses remain above their minimal sustainable levels. Moreover, the paper provide proofs of the equilibria of the original game by Fischer and Mirman (1992).

2.4 Gauteplass and Skonhoft (2017) explore another dimension in the strategic interaction between countries in a fishery: the age structure of the stock. The authors consider a setting in which different age classes of a migratory fish stock stay in two different management areas. The fishery is modelled as a game between two countries that target different cohorts. The equilibrium solutions for this game are obtained under cooperative and non-cooperative management scenarios. As an illustrative example, the authors point out the Norwegian North Atlantic cod fishery where the coastal fleet targets old mature fish and the trawler fleet targets young mature fish. The paper shows how incorporating the age structure of the stock may be crucial to understand the strategic interaction between countries in harvesting shared fish stocks.

2.5 A topic that has received special attention in the literature is the formation of international fisheries agreements (IFAs), such as RFMOs, that involve several countries joining together to manage a fish stock. This has been approached mainly through coalition games. Pintassilgo et al. (2017) extend this literature to the case in which countries' payoffs account not only for direct consumptive values (harvesting profits) but also for nonconsumptive values of the fish stock per se (non-consumptive use values and non-use values). Through a two-stage partition function game, the authors show that accounting for non-consumptive values help to conserve the stock. However, it does not affect the outcome of the game in terms of the prospects for cooperation: the outcome is full noncooperation, regardless of the magnitude of the non-consumptive values and their level of 
asymmetry. Thus, the trap of non-cooperation in transboundary fisheries management persists even when non-consumptive values are accounted for. In order to foster cooperation, it is suggested to strengthen the role of IFAs in the management of the resources and to limit the ability of non-members to free-ride.

2.6 The strategic interaction among fishing agents under uncertainty is, as noted in 1.1, a topic that it is still underexplored. Punt (2017) investigates the role of sunk entry costs in a stochastic sequential transboundary fishery. A fish stock may face uncertainty due to aspects such as climate change, which may drive the entry of new harvesting countries and require sunk investments. The author concludes that sunk entry costs may change significantly the outcome of the game, when compared to the case of no entry costs. In particular, sunk costs can increase the competitive pressure on the fish stock, act as deterrence mechanism, and a commitment device for the new entrants. Hence, entry costs have a critical importance for the strategic behavior of new entrants when facing stock relocation, due for instance to climate change.

2.7 Engwerda (2017) also addresses fisheries management under uncertainty. The author uses a two-player dynamic game and relaxes a standard assumption in this literature: that players restrict to strategies that stabilize the system. Thus, fishermen can pursue a broader class of fishing strategies. It is assumed that fishermen maximize the discounted profits over an infinite time period. The results show that two basic scenarios may occur, depending whether fishermen are short-sighted or not. In the former, every fishermen will harvest a constant amount of fish over time and this amount will not be affected by potential disturbances. In the latter, some fishermen will adopt a "stabilization activity", in which the harvesting strategies depend on the state of the stock. 
2.8 Mullon and Mullon (2017) develop a framework to study competition, cooperation and bargaining options in the presence of financial and technological constraints. The results indicate that levelling the differences of the constraints faced by different fishing agents is conducive to fruitful negotiations and fair sharing of the resources. Moreover, when competition occurs within elementary technological and financial constrains it may lead only to the survival of the most viable fleet. This occurs even further when some agents have objectives other than profit maximization, such as yield maximization, which reduce bargaining possibilities.

2.9 Finally, Marszalec (2017) addresses the role of auctions in fish quota allocation. The paper presents a comprehensive discussion on the relevance of auctions for rights based fisheries. Regarding the practical implementation of auctions for quotas, a few questions are discussed: Which right should be subjected to auction? How rapidly should the transition be made? What policy objectives should the auction address? Through a survey, the author shows that the developments in auction theory provide many solutions for allocations problems in rights based fisheries.

\section{Conclusion}

The application of game theory to fisheries can be traced back to the late 1970s. The UN Third Conference on the Law of the Sea, 1973-1982, leading to the Exclusive Economic Zone (EEZ) regime, was the key event that triggered the interest of researchers on the strategic interaction between fishing fleets. The coming of the EEZ regime made the management of internationally shared fish stocks a major political and economic issue worldwide. During the 1980s and early 1990s, the applications of game theory to fisheries 
focused on transboundary stocks, using a variety of cooperative and non-cooperative games. Thereafter, applications to straddling stocks were developed, through the use of coalition games. Presently, the application of game theory to the management of national/regional fisheries lags far behind the application to international fisheries, and is clearly a new research frontier.

This Special Issue presents a set of current research developments on game theory and fisheries. It shows, among other aspects:

- How cooperation in internationally shared fish stocks can be supported by implic it or explicit threat strategies (Hannesson, 2017);

- The effect of multispecies fisheries management in an international fishery (Górniewicz and Wiszniewska-Matyszkiel, 2017; Salenius, 2017);

- The role of the age structure of the stock in the strategic interactions between harvesting countries (Gauteplass and Skonhoft, 2017);

- How the formation of international fisheries agreements is impacted when nonconsumptive values of the fish stock are accounted for (Pintassilgo et al., 2017);

- The strategic interaction between fishing agents in a context of uncertainty (Engwerda, 2017; Punt, 2017);

- A framework to study competition, cooperation and bargaining options in fisheries under financial and technological constraints (Mullon and Mullon, 2017);

- The role of auctions in rights based fisheries (Marszalec, 2017). 


\section{References}

Bierman H., Fernandez, L., 1993. Game Theory with Economic Applications. AddisonWesley, New York.

Clark, C., 1980. Restricted access to a common property resource, in: Liu, P. (Ed.), Dynamic Optimization and Mathematical Economics. Wiley-Interscience, New York, pp. 117-132.

Engwerda, J., 2017. Stabilization of an uncertain simple fishery management game. Fisheries Research (Special issue on game theory and fisheries).

Fischer, R., Mirman, L., 1992. A Strategic dynamic interaction: Fish wars. Journal of Economic Dynamics and Control 16, 267-287.

Gauteplass, A., Skonhoft, A., 2017. Conflict and cooperation in an age structured fishery. Fisheries Research (Special issue on game theory and fisheries).

Gordon, H.S., 1954. The economic theory of a common property resource: The fishery. Journal of Political Economy 62, 124-142.

Górniewicz, O., Wiszniewska-Matyszkiel, A., 2017. Verification and refinement of a two species Fish Wars model. Fisheries Research (Special issue on game theory and fisheries).

Grønbæk, L., Lindroos, M., Munro, G., Turris, B., 2016. Application of game theory to intra-EEZ fisheries management. Paper prepared for the $18^{\text {th }}$ Biennial Conference of the International Institute of Fisheries Economics and Trade, Aberdeen, Scotland, July 2016.

Grønbæk, L., Lindroos, M., Munro, G., Pintassilgo, P., forthcoming. Game Theory and Fisheries Management: Theory and Applications. Springer International, Cham.

Hannesson, R., 2017. Shared stocks, game theory and the zonal attachment principle. Fisheries Research (Special issue on game theory and fisheries).

Kronbak, L., Lindroos, M., 2006. An enforcement - coalition model: Fishermen and authorities forming coalitions. Environmental and Resource Economics 35, 169-194.

Levhari, D., Mirman, L., 1980. The great fish war: An example using a dynamic CournotNash solution. Bell Journal of Economics 11,322-344.

Marszalec, D., 2007. Auctions for quota: A primer and perspectives for the future. Fisheries Research (Special issue on game theory and fisheries).

Mullon, C., Mullon, C., 2017. A constraint-based framework to study competition and cooperation in fishing. Fisheries Research (Special issue on game theory and fisheries).

Munro, G., 1979. The optimal management of transboundary renewable resources. Canadian Journal of Economics 3, 271-296.

Munro, G., Van Houtte, A., Willmann, R., 2004. The Conservation and Management of Shared Fish Stocks: Legal and Economic Aspects. Food and Agriculture Organization, Fisheries Technical Paper No. 465. FAO, Rome.

Pintassilgo, P., 2003. A coalition game approach to the management of high seas fisheries in the presence of externalities. Natural Resource Modeling 16, 175-197. 
Pintassilgo, P., Finus, M., Lindroos, M., Munro, G., 2010. Stability and success of Regional Fisheries Management Organizations. Environmental and Resource Economics 46, 377402.

Pintassilgo, P, Laukkanen, M., Grønbæk, L., Lindroos, M., 2017. International fisheries agreements and non-consumptive values. Fisheries Research (Special issue on game theory and fisheries).

Punt, M., 2017. Sunk costs equal sunk boats? The effect of entry costs in a transboundary sequential fishery. Fisheries Research (Special issue on game theory and fisheries).

Salenius, F., 2017. International management of North Atlantic pelagic fisheries - the role of competing species and exploiters. Fisheries Research (Special issue on game theory and fisheries).

Vestergaard, N., 2010. Principal-Agent problems in fisheries, in Grafton, R.Q., Hilborn, R., Squires, D., Tait, M., Williams, M. (Eds.), Handbook of Marine Fisheries Conservation and Management. Oxford University Press, Oxford, pp. 563-571.

Wallace, S., Turris, B., Driscoll, J., Bodtker, K., Mose, B., Munro, G., 2015. Canada's Pacific groundfish trawl habitat agreement: A global first in an ecosystem approach to bottom trawl impacts. Marine Policy 60, 240-248.

Wilen, J., 1985. Towards a theory of the regulated fishery. Marine Resource Economics 1, 369-388. 